\title{
Letters
}

All letters are subject to editing and may be shortened. General letters can be sent to bjgpdisclarcgp.org.uk (please include your postal address for publication), and letters responding directly to BJGParticles can be submitted online via eLetters. We regret we cannot notify authors regarding publication. For submission instructions visit: bjgp.org/letters

\section{Revealing the reality of undergraduate GP teaching in UK medical curricula}

Thank you for publishing our article 'Revealing the reality of undergraduate GP teaching in UK medical curricula' in which we highlighted the longstanding problem of underinvestment in general practice teaching in the UK. ${ }^{1}$ One of our key recommendations was for an adequate primary care tariff, which reflects the cost of teaching and simplifies current payment mechanisms'. We are pleased to report that since writing this paper the Department of Health and Social Care (DHSC) in England has for the first time introduced a national minimum tariff for medical student placements in general practice. ${ }^{2}$ We of course welcome this development as a step in the right direction. However, the new minimum tariff of $€ 28000$ per full-time equivalent (FTE) placement per year still falls significantly short of the current tariff for secondary care undergraduate medical placements set at €33 286. ${ }^{3}$ A primary care payment of $€ 28000$ per FTE is also significantly lower than the actual cost of undergraduate teaching in general practice, identified by a national study in England as $€ 41700$ per FTE.4

While there is no doubt that the health economy will be struggling in the wake of the COVID-19 pandemic, recent events surely present yet further evidence of the need to provide all future doctors with highquality experience in general practice and primary care. We strongly urge governing bodies to move fully to a fair and flat tariff for undergraduate placements from 2021 onwards if they are committed to training the future medical workforce that the NHS will surely need.

\section{Hugh Alberti,}

\section{Subdean for Primary and Community} Care, School of Medical Education, Newcastle University Medical School, Newcastle upon Tyne.

Email: hugh.albertianewcastle.ac.uk

\section{Emily Cottrell,}

General Practice Specialty Trainee, School of Medical Education, Newcastle University
Medical School, Newcastle upon Tyne.

Joe Rosenthal,

Professor of Primary Care Education, Research Department of Primary Care and Population Health, University College London, London.

\section{Lindsey Pope,}

Professor of Medical Education, School of Medicine, Dentistry and Nursing, University of Glasgow, Glasgow.

Trevor Thompson,

Professor of Primary Care Education, University of Bristol, School of Social and Community Medicine, Bristol.

\section{REFERENCES}

1. Cottrell E, Alberti H, Rosenthal J, et al. Revealing the reality of undergraduate GP teaching in UK medical curricula: a cross-sectional questionnaire study. Br J Gen Pract 2020; DOI: https://doi. org/10.3399/bjgp20X712325.

2. Department of Health and Social Care. Education and training tariffs: tariff guidance and prices for the 2020-21 financial year. 2020. https://wmw. gov.uk/government/publications/healthcareeducation-and-training-tariff-2020-to-2021 laccessed 10 Sep 2020).

3. Department of Health and Social Care (DHSC). Education and training tariffs: tariff guidance and prices for the 2019-20 financial year. DHSC, 2019.

4. Rosenthal J, McKinley RK, Smyth C, Campbell JL. The real costs of teaching medical students in general practice: a cost-collection survey of teaching practices across England. Br J Gen Pract 2019; DOl: https://doi.org/10.3399/bjgp19X706553.

DOI: https://doi.org/10.3399/bjgp20X712721

\section{Doctors as patients: submission deadline extended}

We would like to thank those who have contributed so far to our book documenting the experience of doctors as patients. In view of the COVID-19 pandemic we felt it was necessary to delay the final compilation and writing in order to include accounts of this new disease and the unprecedented impact it has had on our profession.
If you have a story to share about your experience as a patient during this pandemic then please consider submitting it. See www.whatsinastory.co.uk/doctoraspatient for more details.

Samuel J Finnikin,

Academic GP, University of Birmingham, Birmingham.

Email: finniksjiabham.ac.uk

David A Orlans,

Retired GP, Liverpool.

Rodger Charlton,

Professor of Undergraduate Primary Care Education, Leicester Medical School, Leicester.

Devina Ravall,

GP, London.

DOI: https://doi.org/10.3399/bjgp20X712733

\section{'Bad old habits' ... and what really matters}

Matt Hancock has urged GPs (30 July) that all consultations should be teleconsultations' and that we mustn't 'fall back into bad old habits', thus freeing up clinicians to concentrate on what 'really matters."

Teleconsultations are potentially dangerous for patients and professionals. It is vitally important not only to be able to listen to the patient, but also to see them and to touch them. Without the ability to examine patients and pick up other clues, diagnoses will be missed or delayed.

Teleconsultations may also prevent those who are disadvantaged or in danger at home from seeking appropriate help. Although they may offer convenience for some patients with discrete, clearly defined problems, teleconsultations are incapable of embracing the inherent 'messiness' of most clinical situations.

What really matters is that we maximise opportunities for meaningful therapeutic engagement with patients. It really matters that we do not assume that what has been 
necessary in a crisis represents what patients or clinicians want or need beyond.

The consultation really matters. It is not simply an exchange of facts, diagnoses, and prescriptions. Done well, the consultation is of therapeutic value, especially when embedded within an enduring relationship. If, as Hancock suggested, we are to 'encourage and celebrate generalist skills," then we must retain the consultation at its centre.

We urge caution in mandating a wholesale shift towards teleconsultations without thorough evaluation. Existing research suggests that telephone triage increases workload with no cost savings, and the value of e-consultation and video-consultation remains controversial.

GPs and patients across the UK are on a steep learning curve, working out how to 'do' remote consultations out of necessity, and it is highly likely they will find their place within mainstream practice. However we do believe that some 'bad old habits' may be worth holding on to.

\section{Deborah Swinglehurst,}

Professor of Primary Care, Barts and The London School of Medicine and Dentistry, Queen Mary University of London, London, UK.

Email: d.swinglehurstlaqmul.ac.uk

\section{Chris Dowrick,}

Professor of Primary Medical Care, University of Liverpool, Liverpool, UK.

Iona Heath,

Retired GP, former President of the Royal College of General Practitioners, UK.

\section{Stefan Hjörleifsson,}

Associate Professor, Department of Global Public Health and Primary Care, University of Bergen, Bergen, Norway.

Sally Hull,

Clinical Reader in Primary Care Development, Barts and The London School of Medicine and Dentistry, Queen Mary University of London, London, UK.

\section{David Misselbrook}

Associate Professor of Family Medicine, Royal College of Surgeons in Ireland, Bahrain.

Joanne Reeve,

Professor of Primary Care Research, Hull-
York Medical School, Hull, UK

\section{REFERENCES}

1. Hancock M. The future of healthcare. 2020. https:// www.gov.uk/government/speeches/the-future-ofhealthcare (accessed 10 Sep 2020).

DOI: https://doi.org/10.3399/bjgp20X712745

\section{Could checklists support teams in stressful situations?}

We welcome Grieg et al's debate article about checklists.' Any activity that supports GPs in delivering safe, effective care in time-critical situations is greatly welcomed. However, we would like to take the opportunity to encourage practitioners to adopt a more critical approach when considering the use of checklists.

As Greig et al suggest, the rise of checklists in health care has largely followed their use in the aviation industry, where they provide a safety layer that protects against classic human failings like forgetting, particularly when working under pressurised conditions. But differences between health care and aviation present a challenge for this cognitivist way of understanding checklists. ${ }^{2}$ For example, patient complexity makes healthcare delivery much less amenable to standard operating procedures than aviation. Managing healthcare emergencies relies on seamless functioning of multiple staff members across a wide range of roles from GPs to practice nurses to receptionists - rather than just pilots and cabin crew. Practice treatment rooms and equipment vary from place to place much more than standardised aeroplane cockpits do. This means that checklists may not always be effective, may not transfer well between contexts, or may work in different ways than expected. ${ }^{3}$

We remain convinced about the potential usefulness of checklists, particularly in pressurised, infrequently occurring situations such as emergencies. However, faced with the complex, contextualised nature of health care, we recommend qualitative, sociocultural research to develop a deeper understanding of how they can be made to work effectively and in what contexts. We also recommend road testing of checklists - a process that may be supported by the emerging field of in-situ simulation $^{4}$ to ensure that they work within the realities of real-world general practice. Sarah O'Hare,

GP Academic Research Trainee, Queen's University Belfast, Belfast. Email: sohare774dagmail.com

Gerard Gormley,

Clinical Professor, School of Medicine, Dentistry and Biomedical Sciences, Queen's University Belfast, Belfast.

Richard Conn,

Academic Clinical Lecturer, Queen's University Belfast, Belfast.

\section{REFERENCES}

1. Greig P, Maloney A, Higham H. Emergencies in general practice: could checklists support teams in stressful situations? Br J Gen Pract 2020; DOI: https://doi.org/10.3399/bjgp20X709373.

2. Clay-Williams R, Colligan L. Back to basics: checklists in aviation and healthcare. BMJ Qual Saf 2015; 24(7): 428-431. DOI: 10.1136/bmjqs2015-003957.

3. Urbach DR, Govindarajan A, Saskin R, et al. Introduction of surgical safety checklists in Ontario, Canada. N Engl J Med 2014; 370(11): 1029-1038. DOI: 10.1056/nejmsa1308261.

4. Patterson MD, Geis GL, Falcone RA, et al. In situ simulation: detection of safety threats and teamwork training in a high risk emergency department. BMJ Qual Saf2013; 22(6): 468-477.

DOI: https://doi.org/10.3399/bjgp20X712757

\section{Correction}

In the Research paper by Hayward G, Verbakel JY, Abakar Ismail F, et al. Non-contact infrared versus axillary and tympanic thermometers in children attending primary care: a mixed-methods study of accuracy and acceptability. Br J Gen Pract 2020; DOl: https://doi.org/10.3399/bjgp20X708845, the numbers listed in Table 3 did not tally with Table 4. The authors discovered a coding error for the calculation of secondary outcome of diagnostic accuracy in Table 3, leading to missing values being counted as fever positives. In addition, the total number of participants in Table 2 was incorrect, but all analyses were correctly conducted and reported. To summarise the changes: 1) the total number of participants in Table 2 has been corrected, 2) the analyses in Table 3 have been corrected. Numbers in the text of the results have been adapted accordingly. The Discussion has been modified to reflect these changes (prevalence of fever was lower than reported, sensitivity of the NCITs for fever based on the axillary reading as a reference standard was better than initially reported and equivalent to other literature, but confidence intervals were very wide). No changes were needed to the abstract.

DOI: https://doi.org/10.3399/bjgp20X712769 